\title{
"Fear, Shame and Embarrassment": The Stigma Factor in Post Abortion Care at Komfo Anokye Teaching Hospital, Kumasi, Ghana
}

\author{
Eva Tagoe-Darko ${ }^{1}$ \\ ${ }^{1}$ Department of Geography and Rural Development, Faculty of Social Sciences, Kwame Nkrumah University of \\ Science and Technology, Kumasi, Ghana \\ Correspondence: Eva Tagoe-Darko, Department of Geography and Rural Development, Faculty of Social \\ Sciences, Kwame Nkrumah University of Science and Technology, Kumasi, Ghana. Tel: 233-2-0903-3382. \\ E-mail: motabla_dd@hotmail.com
}

\author{
Received: March 8, 2013 Accepted: May 15, 2013 Online Published: August 1, 2013 \\ doi:10.5539/ass.v9n10p134 URL: http://dx.doi.org/10.5539/ass.v9n10p134
}

\begin{abstract}
Using qualitative data on post abortion care services at the Komfo Anokye Teaching Hospital in Kumasi, Ghana, the paper explored evidence of social stigma as a factor in post abortion care. Results from 6 focus group discussions, 10 narratives and observations identified three areas of stigma. The Patients (perspective and experience), the Providers (the medical environment and setting) and the Community (family, relations and peers). Evidence from the focus group discussions, narratives and observations suggested social stigma as a significant factor in the process of pre-marital sex, abortion and post abortion care. At the individual level there was fear, shame and embarrassment. The medical setting was judgmental, indifferent and/or showed disdain while there was moral consensus, the morality of abortion by family, peers and community. In recognition of the dangers inherent in unsafe abortion outside the medical setting and in view of the fact that death from complications of unsafe abortion is preventable, these findings have implications for intervention and policy. The paper recommended collective effort to addressing all three areas of stigma and post abortion care. Sustained education, sensitization and dissemination using all available channels including traditional teachings and practices to reduce stigma and provide safer alternatives were suggested.
\end{abstract}

Keywords: post abortion care, stigma, pre-marital sex, traditional teachings and practices, Kumasi

\section{Introduction}

The paper attempts to explore evidence of stigma as a factor in post abortion care (PAC) at the Komfo Anokye Teaching Hospital (KATH), Kumasi, Ghana. The study was a follow up to findings from the baseline study, a collaborative research between Kwame Nkrumah University of Science and Technology, School of Medical Sciences and Obstetrics and Gynecology unit / JHU BSPH which examined the quality PAC at the large referral teaching hospital, KATH, in 2000. Results from the initial study indicated among others that there was unsafe abortion with complications, evidence of reporters, the use of abortion as contraceptive, lack of knowledge about abortion law and its legal status as well as lack of post abortion care.

There is increasing recognition of the dangers and long-term complications inherent in informal abortions outside the medical setting. Hospital based studies report anywhere from $25 \%-30 \%$ of maternal mortality as attributable to abortion related complications. In Africa 23,000 women die each year from unsafe abortion accounting for $13 \%$ of all maternal death. The practice of unsafe abortion and associated maternal mortality is very high in Ghana. Available data suggest that more than half $(50 \%)$ of the Obstetrics and Gynecology admissions are due to abortion related complications including incomplete, complete, inevitable or induced (WHO, Program of Action ICPD 1994, 1999).

Baseline study in 2000 showed that quality of PAC at KATH was very poor. It was curative and not preventive. Improving overall reproductive health and PAC was not the core of obstetrics and gynecology training and residents continued traditional practice of dilatation and curettage. KATH provided treatment oriented services - curative care - for post abortion complications, not PAC as framed by the International Project Assistant Services (IPAS). Post abortion care was lacking.

A vast majority $(90 \%)$ of the cases were treated by medical interns and residents. More than $50 \%$ of patients 
could not obtain pain medication, even when requested. Of the cases, $25 \%$ delayed seeking care. Provider-client interaction was poor. Women substituted abortion for contraceptive use and had repeated abortion. Of the cases observed, $70 \%$ never used contraceptives. Family planning counseling was not always provided. Only 7\% received contraceptive counseling and referral to a family planning clinic, while only $3 \%$ requested contraceptive method.

Evidence suggested there was inadequate knowledge of the legal status of abortion among abortion seekers. A de facto illegal nature of abortion prevails, even though in Ghana there has been a flexible abortion law since 1985. Knowledge of legality was also low in the medical environment and setting. Abortion was still considered as illegal even by the physician/nurses and death records avoided abortion as cause of death. (Saifuddin Ahmed et al., 2001; Danso et al., 2002; Tagoe-Darko et al., 2003).

The objectives of the study were done in three (3) areas of stigma: (1) the Individual - Patient/ client perspective and evidence; (2) the Providers - the medical environment and setting and (3) the Community - Family, Relations, Peers.

\section{Data and Methods}

\subsection{Research Design}

This qualitative study was initiated after the preliminary results of the baseline study to confirm and provide further insights into unsafe abortion and PAC. The study was also to link PAC services to family planning, improve counseling, overall quality of care and strategies to improve quality of sustainable PAC services at KATH, Kumasi, Ghana. Qualitative methods were employed to systematically examine the contexts of unsafe abortion, quality of PAC services at the clinic and KATH from the perspective of the clients, practices of service providers and case management at the facility.

Women who participated in the two (2) years PAC exit interviews were invited to participate in the qualitative study when they came for review after treatment for complications arising from unsafe abortion. In all, there were 1,400 case reports with 1,400 exit interviews during the two (2) years of study.

The source of data was basically qualitative, from focus group discussions (FGD), In-depth interviews, personal narratives and observations. However, quantitative data from interviews, hospital and medical records have also been used where needed. These were data from Clinic Case Report forms (Clinical examination and interview: Modified IPAS Standard forms); PAC Exit Interviews; Medical record of PAC patients at Obstetrics and Gynecology, KATH, Kumasi, Ghana.

\subsection{Study Setting}

The study focused on patients in a large referral teaching hospital. These were patients with incomplete abortion and complication of unsafe abortion seen at obstetrics and gynaecology section of KATH, Kumasi. The obstetrics and gynaecology consulting / waiting room and the Family Planning consulting / waiting room were used for the FGD for privacy. The hospital setting provided a convenient place to gather information as patients in hospitals and clinics were often more willing to consent to be interviewed and to provide information.

\subsection{Data Collection Tools and Procedure}

The method was basically qualitative using FGD, narratives and observations. Qualitative methods such as FGD and participant observations are increasingly being used in reproductive health research in order to enhance information obtained from more traditional qualitative data collection methods such as the knowledge, attitudes, beliefs and practices surveys. Researchers and program planners alike are beginning to recognize that qualitative methods such as FGD, narratives and observations can be used to elicit sensitive information on determinants of behaviour such as attitude and social norms, as well as the cultural context in which these behaviours take place. Evidence also suggested that such qualitative methods define the broad social and cultural environment of research topics (Helitzer-Allen, 1994).

Despite theoretical warnings of the limitations of FGD, a recent review of rapid ethnographic techniques found that FGDs are commonly being used as the sole or primary method for collecting sensitive information in health programmes (Helitzer-Allen, 1994).

\subsection{Focus Group Discussions (FGD) and Participants}

The results presented are from six (6) FGDs conducted over a three months period, by members of the project team, with 50 participants aged 17-42 years. The number of participants in each group ranged from six to twelve (6-12). A video film "Put yourself in her shoes", a package on family planning counseling to prevent repeated abortion was shown and discussed with participants (Video by JHCCP / PATH /Zambia Information Service/ 
USAID/ Packard Foundation). Participants and members of the team sat in U-shape or circle. The discussions lasted one to three hours (90-180 minutes). They were recorded and later transcribed with the help of notes taken and observations during the discussions. Narratives of the personal experiences of ten (10) participants who volunteered were recorded.

Participants discussed the film and followed it with the FGD using guided questions. Guided questions for FGD focused on knowledge and reasons for unsafe abortion, methods used for unsafe abortion, consequences, use of abortion as contraceptive, treatment of patients with consequences of unsafe abortion by providers, legality of abortion, knowledge of family planning and contraceptives. Willing participants volunteered and shared their experiences of induced abortion and post abortion care.

Participants were assured of anonymity, confidentiality and they could leave anytime during the discussion. No names were used and no pictures were taken. Informed consent was read and signed by all participants. Teenagers with abortion complications were not willing participants. Marriage was also a critical factor in participation and married women were more willing to share their experiences.

The project team included a demographer/medical sociologist, two social scientists, a nurse and a computer analyst. They were the coordinator, moderator, interviewer, note-taker, equipment operator, and observer respectfully.

\section{Results}

In general, it became evident from the discussions that there was a long history of induced abortion. Abortion was universal across the reproductive age and not limited to younger unmarried women. However, younger women were more vulnerable to unsafe abortion and associated complications. In some instances, abortion was considered to be one among a continuum of birth control options, a kind of contraception. In such cases, the distinction between contraception and terminating a pregnancy was not always clearly made, especially by repeaters.

A broad array of persons performed unsafe abortions. Aside from the woman herself, others included non medical personnel such as friends, relatives and untrained quacks with negligible skills, if any. Those with medical experience included physicians working at clandestine sites or in hospitals operating theatre after hours, midwives, nurses, pharmacists, traditional birth attendants and herbalists.

About $25 \%$ of the study participants delayed seeking care, sometimes staying more than three days with the symptom. Self reporting of induced abortion was also low. Primarily, the patients were referred from the other health facilities to KATH. The provider / client interaction was poor. Pain management was also poor and more than $50 \%$ could not get pain medication even when requested.

Specifically, a review of the transcribed tapes and the notes revealed the following:

\subsection{Unsafe Abortion}

1) Participants had appreciable level of knowledge about unsafe abortion.

2) Most unsafe abortions were initiated by women and men at home.

3) The first call of unsafe abortion was the wayside health facility due to the flexible and friendly payment method.

4) Wayside health operators worsened unsafe abortion conditions.

5) Ghanaian society disapproved of unsafe abortions and social stigma was a significant factor in pre-marital sex, unwanted teenage pregnancy and induced abortion.

6) Pregnancies were terminated due to fear, embarrassment, peer and family pressures, economic hardship, lack of responsible husbands, inadequate preparation for marriage / wedding, and use of multiple partners by some women. Others terminate pregnancies to continue their education.

7) A few of the respondents use abortion as a means of family planning. To them, abortion was considered to be one among a continuum of birth control options.

8) Nurses scorned most mothers, especially unmarried and young females, who attempted induced, unsafe abortions and were admitted at the hospitals.

\subsection{Family Planning}

1) Family planning was about spacing childbirth by couples.

2) The respondents were aware of family planning methods. 
3) Family planning was poorly patronized due to fear of side effects and the unpleasant experiences of friends and relatives who had used family planning methods. Some were afraid to use the pill because they may die.

4) Religious beliefs prevented people from using family planning methods.

5) Urgent call for men to fully participate in family planning.

\section{Discussion}

From the literature, stigma has been defined as "a symbol of disgrace or infamy, a sign of moral blemish or reproach caused by dishonorable conduct". Stigma can be defined as a mark of shame, disgrace or disapproval which resulted in an individual being shunned or rejected by others. Stigma is associated with an individual behaviour which differs from the norm. It involves using negative labels to refer to someone. Stigma puts up walls and works against individuals, such as young females with a history of induced abortion, from seeking the needed help for fear of negative comments and discrimination.

Studies have shown social stigma as a significant factor in the process of pre-marital sex, abortion and post abortion care. Often the stigma and social consequences faced by individuals are as emotionally stressful and debilitating as the physical manifestation of the pregnancy or abortion. Many, especially, the young and unmarried women were not only afraid but also ashamed and embarrassed due to the de facto illegal nature of abortion. In Ghana, although abortion is legal, it still carries stigma for all, but especially, unmarried and single young women with incomplete abortion.

Evidence of stigma are discussed at three (3) levels, the individual (patient / client); the medical, made up of the environment and providers; and the community consisting of the family, friends and peers.

\subsection{Individual Patient - Fear, Shame, Embarrassment}

A social stigma was attached to pregnant, unmarried women and this increased the likelihood that unmarried women would want abortion. Recognition of this social stigma usually led to fear, shame and embarrassment as well as a decline in initial communication with family members. Fear of reaction of parents, family and friends increased secrecy. Generally, absence of stigma was dependent on this secrecy.

The social stigma had serious effect on their lives. Social interaction with friends and families suffered and fear of disclosure affected people financially and prevented them from seeking support and help. Self image was seriously affected as pointed out in the statement below:

"...It is not our fault. Teenage pregnancy can be very embarrassing. So I think if you are not ready to give birth and you get pregnant, you have to abort it to avoid any problem. My boy friend who impregnated me did not want me to abort but I used my own money to abort it to avoid any disgrace" (Unmarried, 28 years, trader).

Individual women internalized and expressed stigma in different ways. Abortion was a horrible experience for most women who worried that they were abetting a murder. In religious circles, abortion was considered a murder and a sin. Some women spoke about the guilt and grief brought by the abortion procedure itself. Some also talked about the stigma and expressed feelings of guilt and shame as evidence from the following statement suggested.

“...A friend of mine aborted because her husband who did not have a good job was not responsible for the pregnancy. The man who impregnated her was someone's husband...." (Married, 35 years, seamstress).

4.2 Community: "A Moral Consensus - Morality of Abortion by Peer and Family". Ghanaian Society Generally Disapproves of Unsafe Abortions

It was evident from the discussions that the Ghanaian society disapproved of unsafe abortions and there was a social stigma associated with such actions. The woman who finds herself with an unwanted pregnancy suffers worst of all because she has brought her suffering upon herself - the idea that she deserves her suffering. The following statement by one participant highlights the agony which one brings on oneself, through her own actions:

"......Most of the time, termination of pregnancy can be attributed to the women themselves. Some have multiple "husbands" (several partners). Thus it becomes difficult for them to know the true father of the pregnancy. Such a situation will force them to abort." (Married, 23 years, trader).

In extreme cases there is death. Young unmarried females are accused of bringing shame and embarrassment to the family and community and are severely beaten, sometimes tragically resulting in death. Stigma attached to 
pre-marital pregnancy and general societal attitude manifest through embarrassment in the patients and hostile reaction from family members as evidence from the following quotations seem to suggest:

“... Most parents become ashamed for their child's pregnancy. Sometimes they become hostile and harass their teenage daughters when they become pregnant. This pushes them to abort the pregnancy" (Married, 32 years, seamstress).

“...Parents put pressure on their unmarried teenage daughters when they become pregnant. This sometimes compels them to abort pregnancies." (Married, 38 years, trader)

“...... I want to say something about the girl who got pregnant. When such girls get pregnant, the way they are handled at home. Sometimes they are even sacked or thrown out of their homes by angry parents who feel disgraced. So they begin to think that, considering the treatment they go through even during pregnancy, they anticipate worse things after the pregnancy. Hence they find ways and means to terminate the pregnancy" (Single, 20 years, unemployed).

"In this community abortion is mostly performed in secret. But girls do it. It has been practiced for a long time....most abortions are still 'backstreet'because it is viewed as a disgrace in the community" (Married, 24 years, hairdresser).

There is stigma of unwanted pregnancy at the community level and the family. Stigma attached to childbearing out of wedlock, resulted in lack of support from family. Women who were not married constituted a special group of abortion seekers who had different needs and behaved differently from the married women. There was significantly higher use of traditional and quack providers among this group, a reflection of the fact that this group are marginalized as a result of both social stigma and exploitation.

\subsection{Medical - Judgmental, Indifference, Overt Disdain}

One of the greatest dangers discussed was indifference or lack of commitment on the part of the medical and nursing staff to provide prompt, attentive and emotionally supportive care. This indirectly doomed women whose lives could easily be saved. Many women who reached medical facilities were met with suspicion and hostility and their treatment deferred while other more "suitable" patients received attention. When dealing with patients in need, judgmental behaviors on the part of health care personnel was considered both medically dangerous and ethically indefensible. There was a moral consensus - the morality of abortion - associated with the complexity of abortion. During the discussions, participants pointed to the insensitivity of service providers, especially the nurses.

"......There was little support for abortion among the medical staff. The nurses shouted roughly at her and added she was not the type who assisted people killing innocent children" (Unmarried, 20 years).

Such perceived judgmental and insensitive medical environment was reflected in the following narratives:

4.4 Narratives

“....At KATH, I was admitted at A3. The nurses were not caring. None of them attended to me to give any medication until the next morning when I was sent to the theatre. On the way to the theatre, I felt extreme abdominal pains, and therefore, could not walk to the theatre. I was given an injection. After some few minutes, the foetus came out without the placenta. All this time the nurses there were there unconcerned, even when other patients called their attention to my condition. I was soaked in blood all night. I was in such a condition until another nurse came to see me and told the nurses in the ward that I was in a very critical condition. The nurses in the ward shamelessly accused me of not answering her questions. The doctor arrived and sent me to the theatre to have the placenta removed. My husband then settled my bills and took me home” (Married, 27 years, trader).

“........About one a month ago, I realized I had blood in my underwear. I went to inform a midwife who advised me that it is normal and advised that I should not do any hard work. Later, I experienced a sharp pain in my stomach. When I went to my room, I noticed blood gushing out profusely. We chartered a taxi to the Polyclinic, KATH. I was put in a wheelchair and sent to A3 for examination and a series of questions. The doctor asked me to go and lie on another bed. All of a sudden, I became unconscious. The nurse gave me drip after collecting money from my sister. All the time the nurse was insulting me. I did not mind her and said nothing to her because I was in pain. The nurses were very unfriendly...." (Single, 31 years, hairdresser).

"...I went to a large hospital in the city. The doctor said, 'you village women are all the same. Cannot keep yourself out of trouble. Don't you understand anything?' After this he said 'bring your mother 
with you or your mother-in-law. I don't want problems afterwards.' Tell me, whom could I bring? How could I tell anyone of my plight? (Separated woman, 18 years) [Ganatra et al, 1998].

Three dissemination workshops were organized after the study. Participants included medical providers, representatives from public and private hospitals and clinic in the metropolis, medical personnel, especially nurses from $\mathrm{O}$ and $\mathrm{G}$, KATH.

The discussions highlighted the need to provide safer alternatives to traditional clandestine abortion methods for safe legal accessible abortion improves health. The need to integrate contraceptive counseling and services, male partner involvement in management of unsafe abortion and other activities to improve post abortion care, was also recognized.

To address these, there was training and setting up of an MVA unit at the Family Planning unit. The Sexual and Reproductive Health unit established a counseling office in the ward (Ward 3) with a permanent family planning nurse. The location of the unit in the ward, among others, emphasized the importance of providing counselling and services directly to post abortion patients and also brought the services closer to them.

\section{Limitations}

Whiles the paper provided insight into the stigma factor associated with induced abortion, it becomes pertinent to highlight the limitation of the information available from discussions and narratives. Abortion is considered a sensitive issue, involves sensitive personal information and associated with cultural sensitivity. Given the sensitive and private nature of abortion related information, even within a legal context, most studies have to deal with problems of underreporting, misrepresentation and miscalculations. In a hospital setting such as this study, information was collected from patients of emergency and complications from unsafe abortion. They had a choice to refuse but the setting proved difficult. This raised ethical issues.

Yet, there was no doubt that accurate figures of abortions induced outside the hospital setting remain unknown as patients were usually unwilling to reveal such information. Due to fear of prosecution or social stigma, information relating to abortion was often difficult to obtain either from clients or providers. Most women seeking abortion and most people providing abortion services do so clandestinely. Most obtain services from untrained professionals in environments failing to meet basic minimal medical standards and most of these abortions are considered unsafe.

\section{Implications}

These findings have implications for the individual, the medical environment, members of the community and at the national level, for both intervention and policy.

There was no doubt that safe legal accessible abortion improved health. At the individual level, there was the need for safer alternatives such as the MVA, in place of the traditional clandestine abortion methods. In addition, special family planning activities, traditional practices and teachings to reduce stigma must be promoted.

In the medical environment and among providers, the importance of sustained sensitization and dissemination of findings, activities to improve post abortion care, provision of counselling and family planning services to post abortion patients needed great emphasis.

Increased participation of community members, partners/ husbands and the active role of men in post abortion care and other family planning activities must be encouraged.

At all levels, sustained education, sensitization and dissemination, using all available channels including traditional teachings and forms to reduce stigma and provide safer alternatives to unsafe abortion were of particular importance.

\section{Conclusion}

Unsafe abortion is a grave area of concern and needs the collective effort of all-the patients, the community, research and medical community, political bodies, members of the general public, etc. The profile of an incomplete abortion patient goes beyond that of the young single schoolgirl that is typically portrayed by providers. In particular, women presenting with incomplete abortions included those older than thirty (30) years.

Emphasis should be on eliminating the need for abortion. Year in, year out, many women die of complications of unsafe abortion. Many women risk degradation, disease and death through abortions. Their deaths are more tragic since nearly all are preventable in one way or the other.

The determinants of unsafe abortion are multifaceted. They include socio-cultural, economic and psychological. Multi-sectoral approach appears to be a plausible way of reducing, if not eliminating, unsafe abortions and also 
improving family planning patronage. Mati et al (cited in Khama Rogo et al, 1998) showed that it was possible to interrupt the cycle of unwanted pregnancy through post-abortion counseling and family planning. A special intervention to reduce or eliminate stigma will greatly reduce unsafe abortion.

A recommended strategy to reduce stigma and shame of pre marital sexual activity and pregnancy is the use of traditional forms of public acceptance and recognition of onset of sexual relations and education during puberty rites and initiation ceremonies. Conferring such public status emphasizes that girls have become adult women The timing and content of such initiation ceremonies as the "dipo", "bragro", "fombo" therefore, may provide a key to the solution and remove the stigma, shame and embarrassment of pre marital sexual activity and pregnancy.

\section{References}

Benson, J. L. A., Nicholson, L. A., Gaffikin, L., \& Kinoti, S. N. (1996). Complication of Unsafe Abortion in Sub-Saharan Africa: A Review. Health Policy Planning, 11(2), 117-131. http://dx.doi.org/10.1093/heapol/11.2.117

Bernstein, P. S. A., \& Rosenfield, G. (1998). Abortion and Maternal health. Int J of O\&G63 Suppl1 S115-122.

Binki, N. J. (1984). Women Hospitalized for abortion complications in Mali. International Family Planning Perspectives, 10(1), 8-12. http://dx.doi.org/10.2307/2948028

Casanueva, E. R., Lisker, A., \& Carnevale, E. A. (1997). Attitude of Mexican physicians toward induced abortion. Int. J. of Obst \& Gyn, 56, 47-52. http://dx.doi.org/10.1016/S0020-7292(96)02787-7

Chapple, A., Ziebland, S., \& McPherson, A. (2004). Stigma, Shame and Blame experienced by patients with lung cancer: qualitative study. $B M J, 328,1470$. http://dx.doi.org/10.1136/bmj.38111.639734.7C

Coeytaux, F. M. (1988). Induced Abortion in sub-Saharan Africa: What we do and do not know. Studies in Family Planning, 19(3), 186-190. http://dx.doi.org/10.2307/1966754

Faundes, A. E. H. (1997). Illegal abortion: Consequences for women's health and the health care system. Int. J. of Obst \& Gyn, 58, 77-83. http://dx.doi.org/10.1016/S0020-7292(97)02860-9

Ganatra, B. R., Hirve, S. S., Walawalkar, S., Garda, L., \& Rao, V. N. (2000). Induced Abortions Among Married Women in Rural Western Maharashtra: Prevalence and Patterns. Presented at Reproductive Health in India: New Evidence and Issues. Tata Management Training Centre, Pune, Maharastra, India.

Ganatra, B., \& Hirve, S. (2002). Induced Abortion among Adolescent Women in rural Maharashtra, India. Reproductive Health Matters, 10(19), 76-85. http://dx.doi.org/10.1016/S0968-8080(02)00016-2

Goyaux, N. (1999). Abortion complications in Abidjan (Ivory Coast) Contraception 60:107-109.

Grimes, D. (2003). Unsafe Abortion: the silent scourge. British Medical Bulletin 67: 99-113. Oxford University Press. http://dx.doi.org/10.1093/bmb/ldg002

Gupte, M. (1997). Abortion needs of women in India: A case study of rural Majarashtra. Reproductive Health Matters, 5(9), 77-86. http://dx.doi.org/10.1016/S0968-8080(97)90008-2

Harden, A., \& Ogden, J. (1999). Young women's experiences of arranging and having abortions. Sociology of Health and Illness, 21(4), 426-444. http://dx.doi.org/10.1111/1467-9566.00165

Helitzer-Allen, D., Makhambera, M., \& Anne-Marie, W. (1994). Obtaining Sensitive Information: The need for more than Focus Groups. Reproductive Health Matters, 3, 75-82. http://dx.doi.org/10.1016/0968-8080(94)90084-1

Khama, R., Orero, S., \& Oguttu, M. (1998) Preventing unsafe abortion in Western Kenya: An innovative approach through private physicians.

Koster-Oyekan, W. (1998). Why resort to illegal abortion in Zambia? Findings from a community based study in Western Province. Soc. Sci. Med, 40(10), 1303-1312. http://dx.doi.org/10.1016/S0277-9536(97)10058-2

Mahomed, K., Healy, J., \& Tandom, S. (1997). Family planning counseling - a priority for post abortion care. Cent. Afr. J Med, 43(7), 205-207.

Mendoz, J. P. (1999). Abortion among adolescent in Cuba. $J$ of Adolescent Health, 24, 59-62. http://dx.doi.org/10.1016/S1054-139X(98)00041-X

Mosaase, M. L., \& Tlebere, P. (1996). Unsafe abortion and post abortion family planning in Africa: The case of Lesotho. Afr J. Fertility Sexual Reproduc. Health, 1, 26-28. 
Pope, C., Ziebland, S., \& Mays, N. (2000). Qualitative research in health care Analysing qualitative data. BMJ, 320, 114-116. http://dx.doi.org/10.1136/bmj.320.7227.114

Portmann, J. (1999). Abortion: Three Rival Versions of Suffering. Cambridge Quarterly of Health Care Ethics, 8, 489-497. http://dx.doi.org/10.1017/S0963180199804101

Reardon, D. C. (2000). Identifying High Risk Abortion Patients. Life Issues. Kochi Japan.

Renne, E. P. (1996). The pregnancy that doesn't stay: The practice and perception of abortion by Ekiti Yoruba women. Soc. Sci. Med, 42(4), 483-494. http://dx.doi.org/10.1016/0277-9536(95)00171-9

Roe, J., Francome, C., \& Bush, M. (1999). Recruitment and training of British Obstetrician-Gynaecologists for abortion provision: Conscientious objections versus opting out.

Singh, K., \& Ratnam, S. S. (1998). The Influence of abortion legislation on maternal mortality. Int. J. of Obst \& Gyn, 63, S122-129.

Solo, J. (1999). Creating Linkages Between Incomplete Abortion treatment and Family Planning Services in Kenya. Studies in Fam. Planning, 30, 1. http://dx.doi.org/10.1111/j.1728-4465.1999.00017.x

Sowell, R. L. (1999). Stories of Violence and Shame. Journal of the Association of Nurses in AIDS Care. 10, 4, 15-16. http://dx.doi.org/10.1016/S1055-3290(06)60307-5

Thapa, S., \& Padhye, S. M. (2001). Induced Abortion in Urban Nepal. International Family Planning Perspectives, 27(3), 144-151. http://dx.doi.org/10.2307/2673836

Varga, C. A. (2002). Pregnancy termination among South African Adolescents. Studies in Family Planning, 33(4), 283-298. http://dx.doi.org/10.1111/j.1728-4465.2002.00283.x

Zabin, L. S. (1993). Do Adolescent want babies? The relationship between attitudes and behavior. J. of Research on Adolescent, 3(1), 67-86. http://dx.doi.org/10.1207/s15327795jra0301_4

\section{Copyrights}

Copyright for this article is retained by the author(s), with first publication rights granted to the journal.

This is an open-access article distributed under the terms and conditions of the Creative Commons Attribution license (http://creativecommons.org/licenses/by/3.0/). 